\title{
Assessment of CROPGRO-Bellpepper model under different nitrogen levels through fertigation
}

\section{A. Raja Gopala Reddy and K. N. Tiwari}

Received : 15.09.2017; Revised : 16.02.2018; Accepted : 25.02.2018

See end of the Paper for authors' affiliation

Correspondence to :

A. Raja Gopala Reddy Department of Agricultural and Food Engineering, Indian Institute of Technology, Kharagpur (W.B.) India Email : rajbckv@gmail.com
- ABSTRACT : Application of optimum quantity of nitrogen during the crop growing period is essential for maximizing the yield profit as well as for reducing the environmental pollution. Regional based blanket application of $\mathrm{N}$ should be replaced by location specific recommendations for higher productivity and increasing the nitrogen use efficiency. Keeping on this view, the present investigation has been carryout during 2014-2016 to assessment of CROPGRO-Bell pepper model under various nitrogen levels through fertigation in subtropical India at Kharagpur, India. The crop growth model was calibrated and well validated under field condition and later the performance was evaluated at increasing temperature. From the field experiments conducted in two years, it was observed the maximum growth attributes, yield and yield attributes were recorded in N100 kg ha-1 which is significantly higher than the remaining treatments. The sub lethal doses of $\mathrm{N}$ levels were at par and the control recorded the lowest values. The crop growth model showed that the effect of increasing temperature upto $1.5^{\circ} \mathrm{C}$ on crop yield is meagre. Crop performance under controlled condition has to be studied.

- KEY WORDS : Fertigation, Nitrogen, CROPGRO-Bell pepper, Drip irrigation

- HOW TO CITE THIS PAPER : Reddy, A. Raja Gopala and Tiwari, K.N. (2018). Assessment of CROPGRO-Bellpepper model under different nitrogen levels through fertigation. Internat. J. Agric. Engg., 11(1) : 101-107, DOI: 10.15740/HAS/IJAE/11.1/101-107. 